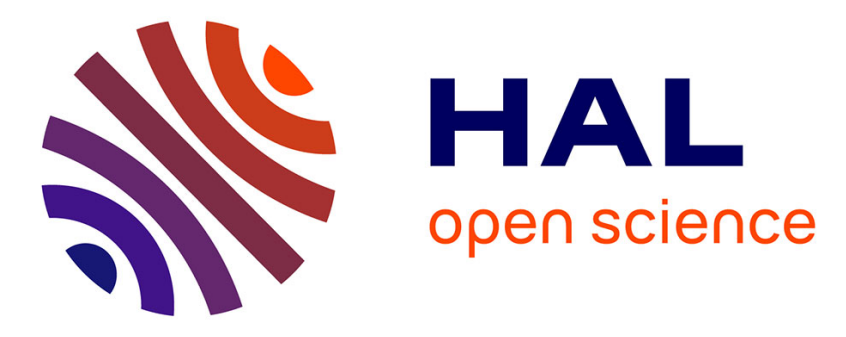

\title{
Reproductive senescence and parental effects in an indeterminate grower
}

Charlotte Depeux, Jean-François Lemaître Lemaître, Jérôme Moreau, François-xavier Dechaume-moncharmont, Tiffany Laverre, Hélène Pauhlac, Jean-Michel Gaillard, Sophie Beltran-Bech

\section{To cite this version:}

Charlotte Depeux, Jean-François Lemaître Lemaître, Jérôme Moreau, François-xavier Dechaumemoncharmont, Tiffany Laverre, et al.. Reproductive senescence and parental effects in an indeterminate grower. Journal of Evolutionary Biology, 2020, 33, pp.1256-1264. 10.1111/jeb.13667 . hal03060301

\section{HAL Id: hal-03060301 https://hal.science/hal-03060301}

Submitted on 14 Dec 2020

HAL is a multi-disciplinary open access archive for the deposit and dissemination of scientific research documents, whether they are published or not. The documents may come from teaching and research institutions in France or abroad, or from public or private research centers.
L'archive ouverte pluridisciplinaire HAL, est destinée au dépôt et à la diffusion de documents scientifiques de niveau recherche, publiés ou non, émanant des établissements d'enseignement et de recherche français ou étrangers, des laboratoires publics ou privés. 


\section{Reproductive senescence and parental effect in an}

\section{2 indeterminate grower}

3

Short running title: Reproductive senescence in the woodlouse

Charlotte DEPEUX ${ }^{1,2}$, Jean-François LEMAÎTRE $^{2}$, Jérôme MOREAU ${ }^{3,4}$, François-Xavier DECHAUME-MONCHARMONT ${ }^{5}$, Tiffany LAVERRE ${ }^{1}$, Hélène PAUHLAC ${ }^{1}$, Jean-Michel GAILLARD $^{2}$, Sophie BELTRAN-BECH ${ }^{1}$

1 Université de Poitiers, Laboratoire Ecologie et Biologie des Interactions, UMR CNRS 7267, 5 rue Albert Turpin, TSA51106 86073 POITIERS Cedex 9, France.

2 Université Lyon 1, Laboratoire de Biométrie et Biologie Evolutive UMR CNRS 558, 43 Boulevard du 11 novembre 1918,69622 Villeurbanne cedex, France.

3 UMR CNRS 6282 Biogéosciences, Université Bourgogne Franche-Comté, 6 Boulevard, Gabriel, 21000 Dijon, France

4 Centre d'Études Biologiques de Chizé, UMR 7372, CNRS \& La Rochelle Université, 79360 Villiers-en-bois, France

5 Univ Lyon, Université Claude Bernard Lyon 1, CNRS, ENTPE, UMR 5023 LEHNA, F-69622, Villeurbanne, France* Corresponding author: charlotte.depeux@gmail.fr

\section{Acknowledgments}

This work was supported by the French ministry of Education, the 2015-2020 State-Region PlanningContract and European Regional Development Fund and intramural funds from the Centre Nationalde la Recherche Scientifique and the University of Poitiers and by a grant from the Agence Nationalede la Recherche (ANR-15-CE32-0002-01). We would like to thank Sylvine Durand, Cybèle Prigot, Ophélie Trainson, Clémentine Préau and Marius Bredon for our constructive exchanges about that work as well as Alexandra Lafitte for technical assistance. We would also like to thank Richard Cordaux and Xavier Bonnet for their insightful comments.

\section{Conflict of Interest}

The authors declare that there is no conflict of interest. 


\section{Abstract}

38 Reproductive senescence is the decrease of reproductive performance with increasing age and

39 can potentially include trans-generational effects as the offspring produced by old parents might

40 have a lower fitness than those produced by young parents. This negative effect may be caused

41 either by the age of the father, mother, or the interaction between the ages of both parents. Using

42 the common woodlouse Armadillidium vulgare, an indeterminate grower, as a biological model,

43 we tested for the existence of a deleterious effect of parental age on fitness components. Contrary

44 to previous findings reported from vertebrate studies, old parents produced both a higher number

45 and larger offspring than young parents. However, their offspring had lower fitness components

46 (by surviving less, producing a smaller number of clutches, or not reproducing at all) than

47 offspring born to young parents. Our findings strongly support the existence of trans-generational

48 senescence in woodlice and contradict the belief that old individuals in indeterminate growers

49 contribute the most to recruitment and correspond thereby to the key life stage for population

50 dynamics. Our work also provides rare evidence that the trans-generational effect of senescence

51 can be stronger than direct reproductive senescence in indeterminate growers.

\section{Keywords}

54 Reproductive success, aging, Armadillidium vulgare, clutch size, indeterminate growth

\section{Introduction}

57 Deciphering the eco-evolutionary roots of inter-individual variation in reproductive success is a

58 long-standing objective in evolutionary biology. Many overall (e.g. temperature, photoperiod) and biotic (e.g. social relationships, population density, predation, food availability) factors can modulate reproductive success in both vertebrates and invertebrates (e.g. Descamps et al., 2008;

61 Geister et al., 2008; Schwanz, 2008; Bertram, 2009; Donelson et al., 2010). Within a given

62 population, individual attributes such as age and size are also associated with reproductive performance in most animals (Clutton-Brock, 1991). However, reproductive success, usually measured as the number of offspring produced at some pre-defined stage, (i.e. conception, birth,

65 or independence of offspring) does not account for the entire process of reproduction. In an evolutionary context where the performance of offspring matters because it shapes Darwinian 
67 fitness (at the individual level) and growth (at the population level), a trans-generational approach 68 is required.

69 Among the factors that influence the fate of offspring, the role of parental age is currently

70 attracting considerable attention (see Lemaître \& Gaillard, 2017 for a review). Evidence of a

71 decrease in reproductive performance at old age has accumulated in the last decades (Nussey et

72 al., 2013) and empirical studies have reported evidence of reproductive senescence in a large

73 range of reproductive traits including clutch size (Tabata \& Teshiba, 2018), juvenile mass or size

74 (Sharp \& Clutton-Brock, 2010; Barks \& Laird, 2016), offspring survival (Packer et al., 1998),

75 offspring reproduction (Ducatez et al., 2012) or offspring lifespan (Lansing, 1947; Barks \&

76 Laird, 2016). Interestingly, when Lansing (1947) published his pioneering study demonstrating a

77 negative effect of parental age on offspring lifespan in rotifers, he made no explicit distinction

78 between the maternal and paternal ages. However, most studies of this process (i.e. the so-called

79 Lansing effect) have focused on maternal age (Lemaitre \& Gaillard, 2017) while old paternal age

80 should also negatively influence offspring performance (Lemaître \& Gaillard, 2017) as a result of

81 decreasing sperm quality with increasing paternal age (Johnson \& Gemmell, 2012). Studies

82 looking at the effect of both maternal and paternal ages as well as their potential interactions are

83 now strongly required (Dzyuba, 2006; Tidière et al., 2018).

84 So far, most studies of parental age effect focused on determinate growers (especially long-lived

85 birds and mammals) (Fay et al., 2016), which are supposed to show stronger senescence than

86 indeterminate growers (Vaupel et al., 2004). In indeterminate growers the number of offspring

87 produced per reproductive attempt is expected to increase with age, which should counter-select

88 reproductive senescence in terms of fecundity (Vaupel et al., 2004; Jones et al., 2014). For

89 example, in fish populations, older and so bigger individuals generally have a higher reproductive

90 success than younger and smaller individuals (Venturelli et al., 2009), which might be due to the

91 production of high quality eggs by old females (e.g. Vallin \& Nissling, 2000 in the Atlantic cod,

92 Gadus morhua). Age classes largely differ in size in indeterminate growers, which makes mating

93 between individuals from distinct cohorts difficult, if not impossible. In such species, both

94 selective pressure and physical constraints during mating can lead to a pattern of size- (and thus

95 age-) assortative mating (Crespi, 1989). Thus, reproductive senescence can be exacerbated by the

96 cumulative effects of both maternal and paternal ages (Lemaitre \& Gaillard, 2017). While

97 investigations of reproductive senescence are mandatory to refine our current understanding of 
the evolution of senescence (Jones \& Vaupel, 2017), such studies are still lacking, especially in invertebrates. Here, we aim to fill this knowledge gap by investigating whether reproductive senescence occurs in an indeterminate grower, the common woodlouse Armadillidium vulgare, and whether advanced parental age negatively influences offspring fitness components.

\section{Materials and Methods}

\section{Biological model}

105 The common woodlouse is a terrestrial isopod that can live up to three years (Paris \& Pitelka, 1962). This species exhibits indeterminate growth and as such large size differences across individuals can be observed. For instance, an old individual could be up to ten times larger than a newly mature individual (Brody et al., 1983). Therefore, physical constraints prevent young individuals to mate with old ones, leading to a pattern of assortative mating in both size and age at the population level (Lefebvre et al., 2019). Female parental care is energetically costly in this species as females actively carry and protect their offspring in a marsupium for a month (Surbida \& Wright, 2001). Offspring develop in this pouch and benefit from a protected environment and nutrients provided by their mother (Surbida \& Wright, 2001). As the incubation of the offspring takes place in the marsupium, the size of the females is closely associated with the number of

All individuals of $A$. vulgare used in our experiment came from a natural population collected in Denmark (Helsingör) in 1982. All the specimens were virgin at the beginning of the study and had been maintained on moistened compost and subjected to Poitiers natural photoperiod (86; $46^{\circ} 34^{\prime} 55^{\prime \prime} \mathrm{N} ; 0^{\circ} 20^{\prime} 10^{\prime \prime} \mathrm{E}$ ) at $20^{\circ} \mathrm{C}$ with food provided ad libitum (i.e. slices of fresh carrots and dried leaves of linden, Tilia $\mathrm{sp}$ ). These conditions were repeated across all experiments.

\section{Differences of reproductive performance between young and old parents}

124 We set up two groups of 40 breeding pairs comprising of one male and one female: one group 125 was made up of old parents (36-months-old) and another group was made up of young ones (12months old). The mass of each individual was initially checked to control for variation within age

127 groups. Young individuals weighed (mean $\pm \mathrm{sd}$ ) $0.081 \mathrm{~g} \pm 0.027 \mathrm{~g}$ and old ones $0.293 \mathrm{~g} \pm 0.044 \mathrm{~g}$.

128 All 80 breeding pairs were weekly monitored throughout 7 months (i.e. during the entire 
129 reproductive season, from January to July) and when females were gravid, they were isolated and

130 placed in boxes with wet paper towel. Only the first clutch produced was used because very few

131 breeding pairs produced a second clutch. We computed the breeding rate according to age (the

132 probability to produce a clutch) for each parental group (i.e. young parents and old parents). We

133 recorded the number of offspring per clutch (hereafter called clutch size). The entire clutch was

134 weighed and then divided by clutch size to obtain the mean offspring mass at birth. The

135 experimental design is presented in Figure 1.

136

Inter-generational traits: offspring mass, survival and reproductive success

138 We monitored the offspring during the most critical period of their lives (0-18 months). Indeed,

139 in the wild, only $11 \%$ of individuals are able to reach 2-years-old (Paris \& Pitelka, 1962). To

140 estimate survival, we counted offspring from the previous breeding pairs a first time at birth, a

141 second time at 5 months of age, then at 12 months of age and finally at 18 months of age (Figure

142 1). The number of surviving offspring counted at each time allowed estimating offspring survival

143 from 0 to 5 months of age, offspring survival from 5 to 12 months of age, offspring survival from

14412 to 18 months of age and total offspring survival (i.e. from 0 to 18 months of age). Offspring

145 were weighed as $12( \pm 1)$ months old and then as $18( \pm 1)$ months old to obtain the offspring

146 mass at 12 months of age and the offspring mass at 18 months of age. To estimate reproductive

147 success of offspring born from young or old parents, we set up, when they are sexually mature

148 (i.e.1-year-old, Paris \& Pitelka, 1962), 4 combinations of 20 breeding pairs (avoiding brothers

149 and sisters): (i) offspring from old parents together, (ii) female offspring from old parents with

150 male offspring from young parents, (iii) females offspring from young parents with male

151 offspring from old parents, and (iv) offspring from young parents together. To avoid pseudo-

152 replication issues (sensu Hurlbert 1984), we analyzed the reproductive status (i.e. reproduction

153 success or failure) of the pair as function of the age group of the female's parents in interaction

154 with the age group of the father' parents.

157 All statistical analyses were performed using the software R 3.6.0 (R Core Development Team 158 2019). For each model, we followed a model selection procedure to identify the minimal model, 159 or the set of adequate models (Anderson \& Burnham, 2002). Starting from the full model, we 
160 ranked all the nested models based on their AIC. Among the top ranked models (delta AIC < 2),

161 we only retained the most parsimonious ones: if one of these models was simply a more complex

162 form of another one listed among the top rank models, for instance because it contained an

163 additional parameter (variable or interaction term), this parameter was ignored and the more

164 complex model was not retained (Galipaud et al., 2014, Supplementary file 1). For the mean

165 offspring mass at birth, at 12 months of age and at 18 months of age as for offspring survival at 5

166 months of age, between 5 and 12 months of age and at 18 months of age we first tested for an

167 effect of clutch size. When clutch size had a statistically significant effect (see Supplementary file

168 2), it was systematically included in the set of considered models (see Berger et al., 2015 for a

169 similar approach).

170 Breeding rate as binary data has been modelled using a generalized linear model (GLM) with

171 binomial distribution with parent's age ('young parents' vs. 'old parents') as a fixed factor.

172 Clutch size was modelled using a linear model (LM) with normal distribution with parent's age

173 as a fixed factor. The mean offspring mass at birth was modelled using a linear model (LM) with

174 a normal distribution because only the average clutch mass was recorded (i.e. individual body

175 mass within a clutch could not be measured at birth). Offspring mass at 12 months of age and

176 offspring mass at 18 months of age were analysed with a linear mixed effect models (LMM) with

177 a normal distribution, using parent's age, offspring sex and their interaction as fixed factors and

178 the breeding pairs identity as a random effect to take into account a potential genetic effect. The

179 survival to 5 months of age was modelled with a generalized linear mixed effect model (GLMM)

180 with a binomial distribution, the parent's age and clutch size were the fixed factors, and the

181 breeding pairs identity was the random effect. The offspring survival from 5 to 12 months of age,

182 from 12 to 18 months of age, and the overall survival (i.e. from 0 to 18 months of age) have been

183 modelled as binary data using generalized linear mixed effect models (GLMM) with a binomial

184 distribution, parent's age and offspring sex and their interaction added to the clutch size were the

185 fixed factors and the breeding pairs identity was used as the random effect. The breeding rate of

186 offspring was modelled with binary data using a generalized linear model (GLM), with mother's

187 age and father's age and their interaction as fixed factors.

188 Finally, reproductive senescence can be masked by the selective disappearance of low quality

189 individuals (Nussey et al., 2008). For a given age larger females produce more offspring in the

190 common woodlouse and body mass is thus generally thought to be a good indicator of individual 
191 quality (Durand et al., 2018). We tested for such relationships by modelling the breeding rate as

192 binary data using a generalized linear model (GLM) with maternal mass set as a fixed factor

193 within the young and old mothers separately. Then, in absence of repeated data on individuals

194 over the life course, we tested for a putative influence of selective disappearance on our results by

195 testing within the old parents group whether the first $50 \%$ of individuals that encounter premature

196 death were lighter than the individuals that survived beyond the median life span. When doing

197 this the effect of mass on survival of the old individual group has been modelled as binary data

198 using a generalized linear model (GLM) with binomial distribution with individual mass, sex and

199 their interaction as fixed factors.

\section{Results}

Differences of reproductive performance between young and old parents

203 Old parents ( 40 breeding pairs) produced 16 clutches, while young parents ( 40 breeding pairs)

204 produced 24 clutches. No detectable difference was found concerning the breeding rate. The

205 model with only the intercept was selected, but if we looked the non-selected model concerning

206 the effect of age on the breeding rate, we found that the breeding rate tended to decrease with

207 increasing parental age (estimate $\pm \mathrm{SE}=-0.76 \pm 0.45$, LR Chisq $1=2.86, \mathrm{P}=0.09$; Table 1; Figure

208 2). Moreover, old parents produced more and heavier offspring than young parents (estimate \pm

$209 \mathrm{SE}=45.15 \pm 12.90, \mathrm{LR} \mathrm{Chisq}_{1}=12.62, \mathrm{P}<0.001$; estimate $\pm \mathrm{SE}=5.63 \mathrm{e} 05 \mathrm{~g} \pm 1.77 \mathrm{e} 05 \mathrm{~g}, \mathrm{LR}$

$210 \mathrm{Chisq}_{1}=12.62, \mathrm{P}=0.001$, respectively; Table 1; Figure 3).

\section{Offspring mass, survival and reproductive success}

213 The offspring mass at 12 and 18 months did not differ between young and old parents (estimate \pm

$214 \mathrm{SE}=0.004 \pm 0.003, \mathrm{LR}_{\text {Chisq }}=1.94, \mathrm{P}=0.16$; estimate $\pm \mathrm{SE}=0.002 \pm 0.004, \mathrm{LR}$ Chisq $1=0.11$,

$215 \mathrm{P}=0.73$ for 12 and 18 months, respectively; Table 1). The cumulative survival (from 0 to 18

216 months) was higher for offspring born from young parents than for offspring coming from old

217 parents (estimate $\pm \mathrm{SE}=0.018 \pm 0.09, \mathrm{LR}$ Chisq $1=3.95, \mathrm{P}=0.04$; Table 1; Figure 4). More

218 specifically, this difference did not occur for the offspring survival between birth and 5 months of

219 age (estimate $\pm \mathrm{SE}=0.18 \pm 0.69$, $\mathrm{LR}$ Chisq ${ }_{1}=0.07, \mathrm{P}=0.79$; Table 1; Figure 4) but is present for

220 the survival from 5 to 12 months (estimate $\pm \mathrm{SE}=-0.90 \pm 0.41$, $\mathrm{LR}_{\mathrm{Chisq}}=4.27, \mathrm{P}=0.04$; Table 1;

221 Figure 4) and from 12 to 18 months (estimate $\pm \mathrm{SE}=-1.06 \pm 0.24$, LR Chisq $1=8.22, \mathrm{P}=0.004$; 
222 Table 1; Figure 4). Reproductive success of offspring was higher for offspring born from young mothers and young fathers than for offspring born from old fathers or old mothers $(0.25 \mathrm{vs.} 0$ for young and old females, respectively, 0.20 vs. 0.05 for young and old males, respectively; LR Chisq $_{1}=15.99, \mathrm{P}<0.001$ and LR Chisq ${ }_{1}=5.06, \mathrm{P}=0.02$; Table 1; Figure 5).

\section{Selective disappearance}

228 The maternal mass did not influence the breeding rate within both the young mothers $\left(\chi^{2}=0.27\right.$, $\mathrm{df}=1, \mathrm{P}=0.59)$ and the old mothers $\left(\chi^{2}=2.31, \mathrm{df}=1, \mathrm{P}=0.12\right)$. We also did not find any link between body mass and survival in the 3 -years-old group $\left(\chi^{2}=1.66, \mathrm{df}=1, \mathrm{P}=0.20\right)$ neither in males nor in females as expressed by the absence of statistically significant interaction between sex and body mass (estimate $\pm \mathrm{SE}=-17.19 \pm 11.44, \mathrm{P}=0.13$ ).

\section{Discussion}

235 In indeterminate growers, reproductive success should increase with age, leading to an absence or 236 a negligible reproductive senescence (Vaupel et al., 2004). At first glance, our results support this 237 prediction as old parents produced clutches containing more offspring than young ones (Vaupel 238 et al., 2004). However, old parents tended to produce a smaller number of clutches than young 239 ones and we detected a trans-generational effect of reproductive senescence because parental age 240 negatively influenced both survival and reproduction of offspring. As we had hardly obtained

241 clutches from offspring of old individuals, we were unable to study the quality of the 242 grandchildren.

243 The effect of the environmental context experienced by the parents (e.g. diet, temperature, 244 pathogen prevalence) on offspring performance has been described for a long time (Mousseau, 245 1998; Curley et al., 2011) but an increasing number of studies have revealed that parental age can 246 also negatively impact offspring survival (Priest et al., 2002; Fox et al., 2003) and reproduction 247 (Priest et al., 2008; Bouwhuis et al., 2010; Ducatez et al., 2012; Schroeder et al., 2015; Lippens 248 et al., 2017). For instance, in Asian elephants (Elephas maximus), older mothers produce 249 offspring with impaired survival (Reichert et al., 2019) and in the rotifers Brachionus 250 manjavacas, maternal age negatively affects offspring survival and reproduction (e.g. egg 251 quality) (Bock et al., 2019). These results are in line with ours as we found that the parent's age 252 has a high impact on offspring survival and reproductive prospects. Moreover, we demonstrated 
253 the occurrence of a trans-generational effect of parental age across generations. We reported that

254 males from old parents reproduced less than males from young parents and this observed effect in

255 males was stronger in females because females from old parents did not reproduce at all.

256 Several mechanisms could be involved in these trans-generational effects, including oxidative

257 stress, telomere inheritance, epigenetics, or parental care (Njajou et al., 2007; Franklin \&

258 Mansuy, 2010). Most studies of the physiological basis of senescence in invertebrates (notably in

259 Drosophila melanogaster and Caenorhabditis elegans) have focused on oxidative stress due to its

260 well-described effect on lifespan (Golden et al., 2002). Parental care could also be impacted by

261 age (Lemaitre \& Gaillard, 2017) notably because the ability of acquiring and storing body

262 reserves often decreases with increasing age, at least in vertebrates (Skogland, 1988; Lecomte et

263 al., 2010). Parental care effects are also well documented in invertebrates, in particular in insects

264 (Wong et al., 2013) but the few studies investigating the effect of age on parental care in

265 invertebrates have provided mixed results (Ivimey-Cook \& Moorad, 2018). In some organisms

266 such as viviparous terrestrial isopods, the maintenance of the reproductive system can be very

267 energetically expensive (Lardies et al., 2004). In the woodlice, females provide nutrients to

268 offspring during the incubation in the marsupium by a fluid called marsupial fluid (Surbida \&

269 Wright, 2001). Thus, both the quality and the quantity of nutrients provided by females in

270 marsupium fluid could determine offspring quality and thereby their viability. Studies

271 investigating how the marsupial fluid properties change with mother's age in the woodlouse and

272 whether such changes might account for the decrease in reproductive success we reported in old

273 individuals are strongly required. Overall, our knowledge on age-specific allocation to maternal

274 and paternal care is still in its infancy in invertebrates, but we can hypothesise that a decrease in

275 maternal care associated to increased oxidative stress and some epigenetic factors (Curley et al.,

276 2011; Guillaumet-Adkins et al., 2017) could contribute to the trans-generational effect observed

277 in woodlouse.

278 One of the grey areas of these results is the source of this trans-generational effect. While many

279 studies have focused on the maternal effect, the paternal effect and the interaction between both

280 effects remain relatively unknown. Among the rare studies that have investigated the influence of

281 both maternal and paternal age, Bouwhuis and colleagues (2015) showed that the trans-

282 generational effects are sex-specific in the common tern, Sterna hirundo. In this species,

283 daughters from old mothers had a lower reproductive success than daughters from young mothers 
and sons from old fathers had a shorter lifespan than sons from young fathers. In the invertebrate

285 Drosophila melanogaster, the effect of parent's age in offspring reproduction differs between

286 sexes: sons were insensitive to maternal age but had reduced reproductive abilities with paternal

287 age when daughters from old mothers showed a decrease in reproductive success (Mossman et

288 al., 2019). Offspring produced by both old mothers and fathers show a substantial modification in

289 reproductive behaviour with an extreme egg dumping (Mossman et al., 2019). Overall, both

290 advanced maternal and paternal ages could have a negative impact on offspring lifetime

291 reproductive success, which can be exacerbated by the strong positive age assortative mating that

292 occurs in $A$. vulgare. In our experiment, it was not possible to tease apart the relative contribution

293 of mother and father ages, notably because trials of mating between cross-aged individuals (e.g.

294 1-year-old individuals* 3-year-old individuals) were unsuccessful. Future experiments would

295 need to investigate the effect of age directly on male or female reproductive traits (e.g. sperm,

296 oocytes), which could play a key role in shaping reproductive senescence patterns (Fricke \&

297 Koppik, 2019; Monaghan \& Metcalfe, 2019). Finally, it is important to notice that the survival of

298 older individuals does not seem to be linked to their mass in our experiment, which suggests that

299 the possible selective disappearance of the lightest individuals (in a given age-class) does not

300 impact our results.

301 Everything else being equal, individuals reaching 3 years of age likely achieve a higher fitness

302 than short-lived individuals, thanks to the much larger number of eggs produced throughout

303 lifetime. However, old individuals suffer from a strong reproductive senescence in terms of

304 offspring quality and why selection did not select for old individuals allocating to offspring

305 quality rather than to offspring quantity can be seen as paradoxical at the light of some recent

306 developments in evolutionary biology of aging, which suggest that reproductive senescence

307 should be absent in indeterminate growing species (Vaupel et al., 2004). However, these results

308 can largely be explained by classic evolutionary theories of aging: i) the proportion of individuals

309 reaching 3 years of age in nature $(<1 \%)$ is far too weak to enable the evolution a new

310 reproductive tactic (Medawar, 1952), and ii) the selection for the production of a large quantity of

311 offspring might come at a cost in late life in terms of offspring quality (Williams, 1957). Thus,

312 our findings have two major implications. First, in the particular case of the woodlouse, these

313 results run counter to studies carried out so far, which have viewed oldest individuals as playing a

314 key role in population dynamics through their ability to produce many offspring (Paris \& Pitelka, 
1962; Dangerfield \& Hassall, 1992). However, our study does not provide information on the consequences of reproductive senescence in terms of population dynamics in the wild. While three-year-old individuals are quite rare $(<1 \%$ of a given cohort are reaching 3 years of age) to be expected to play any detectable role in population dynamics, two-years-old individuals are more common in in the wild (i.e. 13\% of individuals within a given cohort reach this age) and reproductive senescence in terms of decreased offspring viability we demonstrated in our study might negatively influence population recruitment (Paris \& Pitelka, 1962). To better understand the influence of reproductive senescence from a quantitative viewpoint, data on age-specific reproductive success in the wild will be required. Our findings demonstrate that indeterminate growers are likely to show senescence but through different pathways compared to determinate growers.

\section{Bibliography}

Anderson, D.R. \& Burnham, K.P. 2002. Avoiding Pitfalls When Using Information-Theoretic Methods. The Journal of Wildlife Management 66: 912.

Barks, P.M. \& Laird, R.A. 2016. A multigenerational effect of parental age on offspring size but not fitness in common duckweed (Lemna minor). Journal of Evolutionary Biology 29: $748-756$.

Berger, V., Lemaître, J.-F., Gaillard, J.-M. \& Cohas, A. 2015. How do animals optimize the sizenumber trade-off when aging? Insights from reproductive senescence patterns in marmots. Ecology 96: 46-53.

Bertram, B.C.R. 2009. Social factors influencing reproduction in wild lions. Journal of Zoology 177: 463-482.

Bock, M.J., Jarvis, G.C., Corey, E.L., Stone, E.E. \& Gribble, K.E. 2019. Maternal age alters offspring lifespan, fitness, and lifespan extension under caloric restriction. Sci Rep 9: 3138 .

Bouwhuis, S., Charmantier, A., Verhulst, S. \& Sheldon, B.C. 2010. Trans-generational effects on ageing in a wild bird population. Journal of Evolutionary Biology 23: 636-642.

Bouwhuis, S., Vedder, O. \& Becker, P.H. 2015. Sex-specific pathways of parental age effects on offspring lifetime reproductive success in a long-lived seabird. Evolution 69: 1760-1771.

Brody, M.S., Edgar, M.H. \& Lawlor, L.R. 1983. A cost of reproduction in a terrestrial isopod. Evolution 37: 653-655. 
Clutton-Brock, T.H. 1991. The evolution of parental care. Princeton University Press, Princeton, N.J.

350 Crespi, B.J. 1989. Causes of assortative mating in arthropods. Animal Behaviour 38: 980-1000.

351 Curley, J.P., Mashoodh, R. \& Champagne, F.A. 2011. Epigenetics and the origins of paternal effects. Hormones and Behavior 59: 306-314.

Dangerfield, J.M. \& Hassall, M. 1992. Phenotypic variation in the breeding phenology of the woodlouse Armadillidium vulgare. Oecologia 89: 140-146.

Descamps, S., Boutin, S., Berteaux, D. \& Gaillard, J.-M. 2008. Age-specific variation in survival, reproductive success and offspring quality in red squirrels: evidence of senescence. Oikos 117: $1406-1416$.

Donelson, J., Munday, P., McCormick, M., Pankhurst, N. \& Pankhurst, P. 2010. Effects of elevated water temperature and food availability on the reproductive performance of a coral reef fish. Marine Ecology Progress Series 401: 233-243.

Ducatez, S., Baguette, M., Stevens, V.M., Legrand, D. \& Fréville, H. 2012. Complex interactions between paternal and maternal effects: parental experience and age at reproducion affect fecundity and offspring performance in a butterfly. Evolution 66: 3558-3569.

Durand, S., Loiseau, V., Prigot, C., Braquart-Varnier, C. \& Beltran-Bech, S. 2018. Producing offspring in Armadillidium vulgare: Effects of genetic diversity and inbreeding. Evolution \& Development 20: 65-77.

Dzyuba, B. 2006. Effect of parental age and associated size on fecundity, growth and survival in the yellow seahorse Hippocampus kuda. Journal of Experimental Biology 209: 30553061 .

Fay, R., Barbraud, C., Delord, K. \& Weimerskirch, H. 2016. Paternal but not maternal age influences early-life performance of offspring in a long-lived seabird. Proc. R. Soc. B 283: 20152318.

Fox, C.W., Bush, M.L. \& Wallin, W.G. 2003. Maternal age affects offspring lifespan of the seed beetle, Callosobruchus maculatus. Functional ecology 17: 811-820.

Franklin, T.B. \& Mansuy, I.M. 2010. Epigenetic inheritance in mammals: Evidence for the impact of adverse environmental effects. Neurobiology of Disease 39: 61-65.

Fricke, C. \& Koppik, M. 2019. Male reproductive ageing - a tale of the whole ejaculate. Reproduction, doi: 10.1530/REP-18-0579.

Galipaud, M., Gillingham, M.A.F., David, M. \& Dechaume-Moncharmont, F.-X. 2014. Ecologists overestimate the importance of predictor variables in model averaging: a plea for cautious interpretations. Methods in Ecology and Evolution 5: 983-991. 
Geister, T.L., Lorenz, M.W., Meyering-Vos, M., Hoffmann, Klaus.H. \& Fischer, K. 2008. Effects of temperature on reproductive output, egg provisioning, juvenile hormone and vitellogenin titres in the butterfly Bicyclus anynana. Journal of Insect Physiology 54: 1253-1260.

Golden, T.R., Hinerfeld, D.A. \& Melov, S. 2002. Oxidative stress and aging: beyond correlation: Oxidative stress and aging: beyond correlation, T. R. Golden et al. Aging Cell 1: 117-123.

Guillaumet-Adkins, A., Yañez, Y., Peris-Diaz, M.D., Calabria, I., Palanca-Ballester, C. \& Sandoval, J. 2017. Epigenetics and oxidative stress in aging. Oxidative Medicine and Cellular Longevity 2017: 1-8.

Hurlbert, S.H. 1984. Pseudoreplication and the design of ecological field experiments. Ecological Monographs 54: 187-211.

Ivimey-Cook, E. \& Moorad, J. 2018. Disentangling pre- and postnatal maternal age effects on offspring performance in an insect with elaborate maternal care. The American Naturalist 192: $564-576$.

Johnson, S.L. \& Gemmell, N.J. 2012. Are old males still good males and can females tell the difference? BioEssays 34: 609-619.

Jones, O.R., Scheuerlein, A., Salguero-Gómez, R., Camarda, C.G., Schaible, R., Casper, B.B., et al. 2014. Diversity of ageing across the tree of life. Nature 505: 169-173.

Jones, O.R. \& Vaupel, J.W. 2017. Senescence is not inevitable. Biogerontology 18: 965-971.

Lansing, A.I. 1947. A transmissible, cumulative, and reversible factor in aging. J Gerontol 2 : $228-239$.

Lardies, M.A., Cotoras, I.S. \& Bozinovic, F. 2004. The energetics of reproduction and parental care in the terrestrial isopod Porcellio laevis. Journal of Insect Physiology 50: 1127-1135.

Lecomte, V.J., Sorci, G., Cornet, S., Jaeger, A., Faivre, B., Arnoux, E., et al. 2010. Patterns of aging in the long-lived wandering albatross. Proceedings of the National Academy of Sciences 107: 6370-6375.

Lefebvre, F., Richard, F.-J., Moreau, J., Rigaud, T. \& Caubet, Y. 2019. Mass drives mating success in Armadillidium vulgare (Crustacea, Oniscidea). Behavioural Processes 168: 103944.

Lemaître, J.-F. \& Gaillard, J.-M. 2017. Reproductive senescence: new perspectives in the wild. Biological Reviews.

Lippens, C., Faivre, B., Lechenault, C. \& Sorci, G. 2017. Aging parasites produce offspring with poor fitness prospects. Biology Letters 13: 20160888.

Medawar, P.B. 1952. An unsolved problem of biology. College. 
Monaghan, P. \& Metcalfe, N.B. 2019. The deteriorating soma and the indispensable germline: gamete senescence and offspring fitness. Proceedings of the Royal Society B: Biological Sciences 286: 20192187.

Mossman, J.A., Mabeza, R.M.S., Blake, E., Mehta, N. \& Rand, D.M. 2019. Age of both parents influences reproduction and egg dumping behavior in Drosophila melanogaster. Journal of Heredity 110: 300-309.

Mousseau, T. 1998. The adaptive significance of maternal effects. Trends in Ecology \& Evolution 13: 403-407.

Njajou, O.T., Cawthon, R.M., Damcott, C.M., Wu, S.-H., Ott, S., Garant, M.J., et al. 2007. Telomere length is paternally inherited and is associated with parental lifespan. Proceedings of the National Academy of Sciences 104: 12135-12139.

Nussey, D.H., Coulson, T., Festa-Bianchet, M. \& Gaillard, J.-M. 2008. Measuring senescence in wild animal populations: towards a longitudinal approach. Functional Ecology 22: 393406.

Nussey, D.H., Froy, H., Lemaitre, J.-F., Gaillard, J.-M. \& Austad, S.N. 2013. Senescence in natural populations of animals: widespread evidence and its implications for biogerontology. Ageing research reviews 12: 214-225.

Packer, C., Tatar, M. \& Collins, A. 1998. Reproductive cessation in female mammals. Nature 392: $807-811$.

Paris, O.H. \& Pitelka, F.A. 1962. Population characteristics of the terrestrial isopod Armadillidium vulgare in California grassland. Ecology 43: 229-248.

Priest, N.K., Mackowiak, B. \& Promislow, D.E.L. 2002. The role of parental age effects on the evolution of aging. Evolution 56: 927-935.

Priest, N.K., Roach, D.A. \& Galloway, L.F. 2008. Cross-generational fitness benefits of mating and male seminal fluid. Biology Letters 4: 6-8.

Reichert, S., Berger, V., Jackson, J., Chapman, S.N., Htut, W., Mar, K.U., et al. 2019. Maternal age at birth shapes offspring life history trajectory across generations in long lived Asian elephants. Journal of Animal Ecology, doi: 10.1111/1365-2656.13049.

Schroeder, J., Nakagawa, S., Rees, M., Mannarelli, M.-E. \& Burke, T. 2015. Reduced fitness in progeny from old parents in a natural population. Proceedings of the National Academy of Sciences 112: 4021-4025.

Schwanz, L.E. 2008. Chronic parasitic infection alters reproductive output in deer mice. Behavioral Ecology and Sociobiology 62: 1351-1358.

Sharp, S.P. \& Clutton-Brock, T.H. 2010. Reproductive senescence in a cooperatively breeding mammal. Journal of Animal Ecology 79: 176-183. 
Skogland, T. 1988. Tooth wear by food limitation and its life history consequences in wild reindeer. Oikos 51: 238.

Surbida, K. \& Wright, J.C. 2001. Embryo tolerance and maternal control of the marsupial environment in Armadillidium vulgare (Isopoda: Oniscidea). Physiological and Biochemical Zoology 74: 894-906.

Tabata, J. \& Teshiba, M. 2018. Sexual attractiveness and reproductive performance in ageing females of a coccoid insect. Biology Letters 14: 20180262.

Tidière, M., Thevenot, X., Deligiannopoulou, A., Douay, G., Whipple, M., Siberchicot, A., et al. 2018. Maternal reproductive senescence shapes the fitness consequences of the parental age difference in ruffed lemurs. Proceedings of the Royal Society B: Biological Sciences 285: 20181479.

Vallin, L. \& Nissling, A. 2000. Maternal effects on egg size and egg buoyancy of Baltic cod, Gadus morhua. Fisheries Research 49: 21-37.

Vaupel, J., Baudisch, A., Dölling, M., A. Roach, D. \& Gampe, J. 2004. The case for negative senescence. Theoretical Population Biology 65: 339-351.

Venturelli, P.A., Shuter, B.J. \& Murphy, C.A. 2009. Evidence for harvest-induced maternal influences on the reproductive rates of fish populations. Proc. R. Soc. B 276: 919-924.

Williams, G.C. 1957. Pleiotropy, natural selection, and the evolution of senescence. Evolution 11: 398-411.

Wong, J.W.Y., Meunier, J. \& Kölliker, M. 2013. The evolution of parental care in insects: the roles of ecology, life history and the social environment: The evolution of parental care in insects. Ecological Entomology 38: 123-137.

Figure's Captions

Figure 1: Experimental Design.

Figure 2: Breeding rate according to individual's age.

Figure 3: Number (A) and Mass (B) of offspring per clutch according to their parent's age. 
482 The thick line depicts the median, the box the interquartile range, and the whisker are bounded to 483 the most extreme data point within 1.5 the interquartile range. The outliers outside this range are 484 displayed as open circles. ** means $\mathrm{p}<0.01$.

486 Figure 4: Offspring survival according to their parent's age.

487 Mean proportion of offspring surviving ( $+/$ - bootstrapped $95 \%$ confidence interval) at 5 months 488 of age, 12 months of age, and 18 months of age. Each data point corresponds to one clutch and 489 was plotted as grey dots with a slight jitter added to distinguish adjacent points.

491 Figure 5: Graphical display of the interactive effect of offspring sex and parental age on offspring 492 reproductive success. 